\title{
Comparison of Carcass and Meat Quality Traits among Three Rabbit Breeds
}

\author{
Jie Wang, Yuan Su, Mauricio A. Elzo', Xianbo Jia, Shiyi Chen, and Songjia Lai ${ }^{*}$ \\ College of Animal Science and Technology, Sichuan Agricultural University, Chengdu, Sichuan 611130, China \\ ${ }^{1}$ Department of Animal Science, University of Florida, Gainesville, Florida 32611, USA
}

\begin{abstract}
The objective of this study was to compare carcass composition and meat quality traits in the longissimus dorsi and biceps femoris muscles in the Hyla, Champagne and Tianfu Black rabbit breeds. Tianfu Black rabbits had the heaviest head, skin, thoracic viscera and commercial carcass percentage $(p<0.05)$. In addition, Tianfu Black had the highest $\mathrm{pH}_{0 \mathrm{~h}}$ value, followed by the Champagne and Hyla breeds $(p<0.01)$ in the longissimus dorsi and biceps femoris muscles. Tianfu Black had a higher a* $(0 \mathrm{~h}$ and $24 \mathrm{~h})$ than the other two breeds in both longissimus dorsi and biceps femoris muscles $(p<0.05)$. The Hyla, Champagne, and Tianfu Black breeds showed a similar pattern of differences for meat quality traits $\left(\mathrm{pH}, \mathrm{L}^{*}, \mathrm{a}^{*}\right.$ and $\left.\mathrm{b}^{*}\right)$ measured in fresh meat $(0 \mathrm{~h})$ and meat stored for $24 \mathrm{~h}$. Hyla had the highest IMF values of the three breeds $(p<0.01)$. The lower intramuscular fat of Tianfu Black and Champagne rabbits gives them an advantage over Hyla rabbits among most consumers seeking lean rabbit meat.
\end{abstract}

Keywords: rabbit meat, breed, carcass composition, meat quality

Received September 23, 2015; Revised November 2, 2015; Accepted November 2, 2015

\section{Introduction}

In European countries and the Mediterranean area, people have consumed rabbit meat for a long time. Rabbit meat has lower cholesterol content and higher levels of protein with essential amino acids than meat from other animal species (Dalle Zotte and Szendro, 2011). In addition, rabbit meat can be regarded as a functional food because of its potential for improvement in state of health and reduction of disease risk (Dalle Zotte and Szendro, 2011). Rabbit meat provides consumers with rich nutritive and bioactive compounds such as PUFA, DHA, and selenium to improve physiological functions. In addition, the low $\mathrm{n}-6 / \mathrm{n}-3$ ratio in rabbit meat helps control cardiovascular and other chronic diseases. In the past 50 years, rabbit meat production in the world has increased 2.5 fold; 1.6 million tons were produced in 2009. China, Italy, Spain and France are the main rabbit meat producers (FAOSTAT, 2010). In commercial rabbit breeding, acceptable meat quality standards are one of the most important limiting fac-

\footnotetext{
*Corresponding author: Songjia Lai, College of Animal Science and Technology, Sichuan Agricultural University, Huimin road, 611130 Chengdu, China. Tel: +86-28-86291010, Fax: +86-2886291010, E-mail: wjie5199@gmail.com
}

tors for the economic output of a farm unit (Rotolo et al., 2013). Color, intramuscular fat (IMF) content, and $\mathrm{pH}$ value are all typical meat quality parameters (Dalle Zotte, 2002).

Hyla is a productive breed that is widely used in crossbreeding programs around the world (Hamouda et al., 1990). Hyla is a breed that has fast growth and high feed conversion as well as large litter size and high survival rate. Champagne displayed a high growth rate in young rabbits and was the most productive among medium-sized breeds (Bolet et al., 2004). Champagne is famous for its special fur and high meat production. Tianfu Black is a Chinese indigenous breed developed by the Sichuan Agricultural University in 2001. Currently, Tianfu Black rabbits are popular among Chinese breeders, but it is not well-known elsewhere the world. No research comparing carcass and meat quality traits among these three mediumsize rabbit breeds currently exists in China. Thus, the objective of this research was to compare carcass and meat quality traits in longissimus dorsi and biceps femoris muscles in the Hyla, Champagne, and Tianfu Black rabbit breeds. Two muscles were considered in this research because $\mathrm{pH}$ levels and rates of metabolism have been found to be dissimilar in different rabbit muscles (Blasco et al., 1990; Ouhayoun et al., 1983, 1988; Vigneron et al., 1976).

(9)This is an open access article distributed under the terms of the Creative Commons Attribution Non-Commercial License (http://creativecommons.org/licences/ by-nc/3.0) which permits unrestricted non-commercial use, distribution, and reproduction in any medium, provided the original work is properly cited. 


\section{Materials and methods}

\section{Animals}

This study was carried out at the experimental rabbitry of the Institute of Animal Genetics and Breeding, Sichuan Agricultural University, China. A total of 340 rabbits (168 males and 172 females) were used in this study. The number of rabbits by breed was 130 Hyla, 130 Champagne and 80 Tianfu Black. Rabbits were reared in individual cages after weaning at 6 weeks of age and fed ad libitum with a commercial diet using standard feeding and management protocols (NRC, 1977).

\section{Carcass traits}

Rabbits were slaughtered at 10 wk of age. The slaughter and carcass dissection procedures followed the World Rabbit Science Association (WRSA) recommendations (Blasco and Ouhayoun, 1996). The slaughter weight, head, skin, thoracic viscera (heart, lungs, trachea, esophagus and thymus), liver, kidneys, commercial carcass (includes head, thoracic viscera, liver and kidneys), reference carcass (no head or viscera) was weighed. Percentages of head, thoracic viscera, liver, kidneys and dissectible fat were calculated relative to the commercial carcass weight. Percentage of skin relative to slaughter weight as well as percentages of commercial and reference carcass weights relative to slaughter weight (dressing percentage) were also computed (Peiretti et al., 2013).

\section{Meat quality traits}

Measurements of $\mathrm{pH}\left(\mathrm{pH}_{0 \mathrm{~h}}\right)$ and color $\left(\mathrm{L}^{*}{ }_{0 \mathrm{~h}}, \mathrm{a}^{*}{ }_{0 \mathrm{~h}}, \mathrm{~b}^{*}{ }_{0 \mathrm{~h}}\right)$ were taken within $15 \mathrm{~min}$ after slaughter. Subsequently, after carcasses had been chilled for 24 at $4^{\circ} \mathrm{C}$ measurements were taken for $\mathrm{pH}\left(\mathrm{pH}_{24 \mathrm{~h}}\right)$, color $\left(\mathrm{L}^{*}{ }_{24 \mathrm{~h}}, \mathrm{a}^{*}{ }_{24 \mathrm{~h}}, \mathrm{~b}^{*}{ }_{24 \mathrm{~h}}\right)$, and intramuscular fat (IMF). Measurements of $\mathrm{pH}$, IMF and color were taken from the biceps femoris and longissimus dorsi muscles. The $\mathrm{pH}$ measurements were taken with a probe using a $\mathrm{pH}$ meter (Model PH-STAR CPU, Meister ${ }^{\circ}$, Germany). The probe was inserted directly into the muscle to a depth of $3 \mathrm{~mm}$. The objective color was measured by using a Konica Minolta colormeter modal (CR-400, Japan) and the CIELAB system. Color data were expressed in terms of Lightness $\left(\mathrm{L}^{*}\right)$, redness $\left(\mathrm{a}^{*}\right)$ and yellowness $\left(b^{*}\right)$. Lightness $\left(\mathrm{L}^{*}\right)$ ranged from black $(0)$ to white $(100)$, redness $\left(a^{*}\right)$ ranged from green $(-60)$ to red $(+60)$ and yellowness $\left(b^{*}\right)$ ranged from blue $(-60)$ to yellow $(+60)$. The IMF was analyzed using the modified Soxhlet method (AOAC, 1980).

\section{Statistical analysis}

Carcass and meat quality traits were analyzed using the following linear model:

$$
Y_{i j k}=\mu+B_{i}+S_{j}+e_{i j k}
$$

Where $Y_{i j k}$ was a meat quality trait, $\mu$ was the overall mean for each trait, $B_{i}$ was the breed effect, $S_{j}$ was the fixed sex effect, and $e_{i j k}$ was the random error. Least squares means and their standard errors were computed for each breed. Breed least squares means were compared using Bonferroni t-tests. Computations were carried out using the general linear model (GLM) procedure of SPSS 21 (IBM, USA).

\section{Results and Discussion}

\section{Carcass traits}

Least squares means for carcass traits and dressing percentages in three rabbit breeds are presented in Table 1. No significant differences in slaughter weight was found among the three rabbit breeds $(p>0.05)$ which indicated that the two exotic breeds (Hyla and Champagne) or local breed (Tianfu Black) had similar growth rates under the feeding levels and handling techniques utilized in the present study.

Tianfu Black rabbits had the highest head percentage, followed by Champagne, whereas Hyla had the lightest heads. In addition, skin percentage in Tianfu Black was significantly higher than in the other two breeds $(p<0.01)$. Lighter skins in the Hyla and Champagne rabbits may have given them an advantage in heat dissipation (Zeferino et al., 2013) relative to Tianfu Black rabbits. The substantially higher head and skin percentages of Tianfu Black would help farmers easily distinguish these rabbits from other medium-size breeds.

Significant differences between the three rabbit breeds existed for visceral organs (Table 1). Tianfu Black rabbits had heavier thoracic viscera than Hyla and Champagne rabbits $(p<0.05)$. Champagne and Tianfu Black had similar liver and kidney percentages which were higher than that of Hyla $(p<0.05)$. Thoracic viscera, liver and kidney are important organs to ensure that an animal has a healthy body and high productivity. Pascual and Pla (2007) suggested that higher head and thoracic viscera percentages may be due to lower degree of maturity of an animal. Commercial carcasses of Tianfu Black rabbits were significantly heavier than those of the Hyla and Champagne rabbits $(p<0.05$; Table 1$)$. However, there was no signifi- 
Table 1. Least squares means for carcass traits and dressing percentages in three rabbit breeds

\begin{tabular}{ccccc}
\hline \hline Trait & Hyla & Champagne & Tianfu Black & $P$-value \\
\hline Slaughter weight (g) & $2230 \pm 12$ & $2244 \pm 11$ & $2231 \pm 9$ & 0.208 \\
Head (\%) & $8.58 \pm 0.23 \mathrm{Bb}$ & $9.24 \pm 0.17 \mathrm{Ba}$ & $11.34 \pm 0.28 \mathrm{~A}$ & 0.004 \\
Skin (\%) & $12.63 \pm 0.23 \mathrm{Bb}$ & $13.36 \pm 0.18 \mathrm{Ba}$ & $15.63 \pm 0.25 \mathrm{~A}$ & 0.006 \\
Thoracic viscera (\%) & $1.28 \pm 0.04 \mathrm{~b}$ & $1.19 \pm 0.03 \mathrm{~b}$ & $1.40 \pm 0.05 \mathrm{a}$ & 0.014 \\
Liver (\%) & $3.31 \pm 0.08 \mathrm{~b}$ & $3.79 \pm 0.07 \mathrm{a}$ & $3.78 \pm 0.08 \mathrm{a}$ & 0.012 \\
Kidney (\%) & $1.08 \pm 0.05 \mathrm{~b}$ & $1.30 \pm 0.06 \mathrm{a}$ & $1.27 \pm 0.07 \mathrm{a}$ & 0.036 \\
Commercial carcass (\%) & $62.71 \pm 0.51 \mathrm{~b}$ & $63.15 \pm 0.39 \mathrm{~b}$ & $64.87 \pm 0.41 \mathrm{a}$ & 0.032 \\
Reference carcass (\%) & $54.71 \pm 0.41$ & $55.14 \pm 0.30$ & $55.98 \pm 0.35$ & 0.057 \\
\hline
\end{tabular}

The data are expressed as least square means \pm standard errors (Means $\pm \mathrm{SE}$ ).

Values with different superscripts within the same row differ significantly at $p<0.05(\mathrm{a}, \mathrm{b})$ and $p<0.01(\mathrm{~A}, \mathrm{~B})$.

cant differences among these three rabbit breeds for reference carcass percentages.

Paci et al. (2012) reported different percentages of skin, head, liver, kidney and reference carcasses in a local rabbit breed and commercial hybrid rabbits in Italy. Similarly, differences in skin, thoracic viscera, liver, kidney, commercial and reference carcass percentages were found between Botucatu and New Zealand White $\times$ Botucatu breed groups under three stress temperatures (Zeferino et al., 2013) and in a local rabbit population in Tuscany (Italy) in indoor and outdoor housing systems (D'Agata et al., 2009). Slaughter trait differences were also found in various large, medium, and small rabbit breeds (Chiericato et al., 1994; Pla et al., 1996; Tùmová et al., 2010). However, Ortiz Hernández and Rubio Lozano (2001) reported that breed and sex had no influence on carcass muscle percentage in New Zealand, Californian, Chinchilla, and Rex breeds in Mexico.

\section{Meat quality traits}

Table 2 and 3 show least squares means for longissimus dorsi and biceps femoris meat quality traits. Tianfu Black rabbits had higher $\mathrm{pH}_{0 \mathrm{~h}}$ for longissimus dorsi $(p<0.009$; Table 2) and biceps femoris ( $p<0.012$; Table 3 ) than Hyla and Champagne rabbits). Conversely, Tianfu Black had lower $\mathrm{pH}_{24 \mathrm{~h}}$ than Hyla and Champagne rabbits for longissimus dorsi $(p<0.006$; Table 2$)$. In addition, the lower $\mathrm{pH}_{24 \mathrm{~h}}$ for biceps femoris in Tianfu Black than in Hyla and Champagne rabbits was nearly significant $(p<0.054$; Table 3). Hyla and Champagne rabbits had similar $\mathrm{pH}_{0 \mathrm{~h}}$ and $\mathrm{pH}_{24 \mathrm{~h}}$ values for both muscles. Values of $\mathrm{pH}_{0 \mathrm{~h}}$ were higher than values of $\mathrm{pH}_{24}$ in Tianfu Black, Hyla and Champagne. Lastly, values of $\mathrm{pH}_{0 \mathrm{~h}}$ and $\mathrm{pH}_{24 \mathrm{~h}}$ in longissimus dorsi were similar to corresponding values in biceps femoris in these three breeds. Our $\mathrm{pH}_{24 \mathrm{~h}}$ values were similar to those of Mazzone et al. (2010) who reported $\mathrm{pH}_{24 \mathrm{~h}}$ in male rabbits subjected to smooth $\left(\mathrm{pH}_{24 \mathrm{~h}}=5.79\right)$ and rough loading methods $\left(\mathrm{pH}_{24} \mathrm{~h}=5.81\right)$.

Muscles have been found to possess a variety of different chemical components. For example, slow red fibers are rich in oxidative enzymes, but rapid white fibers are rich in both glycogen and glycolytic enzymes. These enzymatic differences lead to differences in muscle fiber topology. This has been called muscular heterogeneity. Muscular heterogeneity would produce differences in acidification kinetics and the ultimate $\mathrm{pH}$ in different muscles (Blasco and Piles, 1990; Nath and Rao, 1985; Niedzwiadek et al., 1983; Osman, 1991; Renou et al., 1986). In our case, differences in $\mathrm{pH}$ found in the longissimus dorsi and biceps femoris muscles here suggest that the acidification process in these two muscles differed in the three breeds. The $\mathrm{pH}$ also affects the appearance of raw meat and the tenderness of cooked meat. On the other hand, muscle ultimate $\mathrm{pH}$ has an important influence on meat quality (Watanabe et al., 1996) and is related to the rate of glycogen breakdown and liberation of lactate post-slaughter. Thus, our goal was to achieve an ultimate $\mathrm{pH}$ a little lower than 6.0 by $24 \mathrm{~h}$ (Table 2, Table 3). This was considered to be essential for good product quality (Mach et al., 2008; Terlouw, 2005). A pH substantially lower than 6.0 (e.g., 5.0) would make the meat too firm and dry because the myofibrillary network would shrink and water holding capacity (WHC) would decrease.

Least squares means for longissimus dorsi (Table 2) showed that there were no significant differences among the three rabbit breeds for $\mathrm{L}^{*}{ }_{0 \mathrm{~h}}$ and $\mathrm{L}^{*}{ }_{24} \mathrm{~h}$. Values of $\mathrm{a}^{*}{ }_{0 \mathrm{~h}}$ in Tianfu Black rabbits were significantly different from $\mathrm{a}^{*}{ }_{0 \mathrm{~h}}$ values in Hyla and Champagne breeds $(p<0.01)$, but there was no significant differences between Hyla and Champagne breeds $(p>0.05)$. The value of $\mathrm{a}^{*}{ }_{24 \mathrm{~h}}$ in Tianfu Black rabbits was significantly higher than that of Hyla rabbits $(p<0.05)$, and Champagne rabbits had no significant differences with Tianfu Black and Hyla rabbits ( $p>$ $0.05)$. Tianfu Black rabbits had a significantly higher $\mathrm{b}^{*}{ }_{0 \mathrm{~h}}$ 
Table 2. Least squares means for longissimus dorsi meat quality traits in three rabbit breeds

\begin{tabular}{ccccc}
\hline \hline Trait & Hyla & Champagne & Tianfu Black & $P$-value \\
\hline $\mathrm{pH}_{0 \mathrm{~h}}$ & $6.56 \pm 0.05 \mathrm{~B}$ & $6.48 \pm 0.04 \mathrm{~B}$ & $6.67 \pm 0.05 \mathrm{~A}$ & 0.009 \\
$\mathrm{pH}_{24 \mathrm{~h}}$ & $5.80 \pm 0.03 \mathrm{~A}$ & $5.76 \pm 0.01 \mathrm{~A}$ & $5.66 \pm 0.02 \mathrm{~B}$ & 0.006 \\
$\mathrm{~L}^{*}{ }_{0 \mathrm{~h}}$ & $50.29 \pm 0.53$ & $49.05 \pm 0.59$ & $48.76 \pm 0.74$ & 0.244 \\
$\mathrm{~L}^{*}{ }_{24 \mathrm{~h}}$ & $59.96 \pm 0.74$ & $59.31 \pm 0.63$ & $58.54 \pm 0.45$ & 0.286 \\
$\mathrm{a}^{*}{ }_{0 \mathrm{~h}}$ & $4.25 \pm 0.43 \mathrm{~B}$ & $3.99 \pm 0.31 \mathrm{~B}$ & $5.86 \pm 0.48 \mathrm{~A}$ & 0.003 \\
$\mathrm{a}^{*}{ }_{24 \mathrm{~h}}$ & $4.09 \pm 0.37 \mathrm{~b}$ & $4.63 \pm 0.35 \mathrm{ab}$ & $5.46 \pm 0.40 \mathrm{a}$ & 0.048 \\
$\mathrm{~b}^{*}{ }_{0 \mathrm{~h}}$ & $2.29 \pm 0.27 \mathrm{~b}$ & $2.52 \pm 0.21 \mathrm{ab}$ & $3.06 \pm 0.28 \mathrm{a}$ & 0.044 \\
$\mathrm{~b}^{*}{ }_{24 \mathrm{~h}}$ & $4.88 \pm 0.29 \mathrm{~B}$ & $6.66 \pm 0.32 \mathrm{~A}$ & $4.64 \pm 0.32 \mathrm{~B}$ & 0.008 \\
$\mathrm{IMF}(\%)$ & $1.411 \pm 0.81 \mathrm{~A}$ & $0.017 \pm 0.001 \mathrm{~B}$ & $0.021 \pm 0.001 \mathrm{~B}$ & 0.001 \\
\hline
\end{tabular}

The data are expressed as least square means \pm standard errors (Means $\pm \mathrm{SE}$ ).

Values with different superscripts within the same row differ significantly at $p<0.05(\mathrm{a}, \mathrm{b})$ and $p<0.01$ (A, B).

Table 3. Least squares means for biceps femori meat quality traits in three rabbit breeds

\begin{tabular}{ccccc}
\hline \hline Trait & Hyla & Champagne & Tianfu Black & $P$-value \\
\hline $\mathrm{pH}_{0 \mathrm{~h}}$ & $6.42 \pm 0.07 \mathrm{~B}$ & $6.44 \pm 0.04 \mathrm{~B}$ & $6.75 \pm 0.06 \mathrm{~A}$ & 0.012 \\
$\mathrm{pH}_{24 \mathrm{~h}}$ & $5.82 \pm 0.02$ & $5.81 \pm 0.01$ & $5.70 \pm 0.02$ & 0.054 \\
$\mathrm{~L}^{*}{ }_{0 \mathrm{~h}}$ & $51.71 \pm 0.73 \mathrm{~b}$ & $51.90 \pm 0.47 \mathrm{~b}$ & $54.07 \pm 0.53 \mathrm{a}$ & 0.016 \\
$\mathrm{~L}^{*}{ }_{24 \mathrm{~h}}$ & $63.19 \pm 0.74$ & $61.87 \pm 0.67$ & $61.29 \pm 0.66$ & 0.198 \\
$\mathrm{a}^{*}{ }_{0 \mathrm{~h}}$ & $3.11 \pm 0.38 \mathrm{~b}$ & $3.31 \pm 0.25 \mathrm{~b}$ & $4.67 \pm 0.43 \mathrm{a}$ & 0.011 \\
$\mathrm{a}^{*}{ }_{24 \mathrm{~h}}$ & $3.99 \pm 0.38 \mathrm{~b}$ & $4.04 \pm 0.29 \mathrm{~b}$ & $5.10 \pm 0.43 \mathrm{a}$ & 0.041 \\
$\mathrm{~b}^{*}{ }_{0 \mathrm{~h}}$ & $1.46 \pm 0.22 \mathrm{C}$ & $2.18 \pm 0.18 \mathrm{~B}$ & $3.12 \pm 0.18 \mathrm{~A}$ & 0.001 \\
$\mathrm{~b}^{*}{ }_{24 \mathrm{~h}}$ & $6.20 \pm 0.35 \mathrm{~A}$ & $6.75 \pm 0.36 \mathrm{~A}$ & $5.20 \pm 0.32 \mathrm{~B}$ & 0.008 \\
$\mathrm{IMF}(\%)$ & $2.245 \pm 0.073 \mathrm{~A}$ & $0.031 \pm 0.004 \mathrm{~B}$ & $0.030 \pm 0.003 \mathrm{~B}$ & 0.001 \\
\hline
\end{tabular}

The data are expressed as least square means \pm standard errors (Means $\pm \mathrm{SE}$ ).

Values with different superscripts within the same row differ significantly at $p<0.05(\mathrm{a}, \mathrm{b})$ and $p<0.01$ (A, B, C).

than Hyla rabbits $(p<0.05)$, and Champagne rabbits had no significant differences with Tianfu Black and Hyla rabbits $(p>0.05)$. Champagne rabbits had significantly higher values of $\mathrm{b}^{*}{ }_{24 \mathrm{~h}}$ than Hyla and Tianfu Black rabbits $(p<$ $0.01)$, but no significant differences were found between Hyla and Tianfu Black rabbits $(p>0.05)$. Hyla rabbits had a significantly higher IMF than Champagne and Tianfu Black rabbits $(p<0.01)$, and there was no significant differences between Champagne and Tianfu Black rabbits $(p>0.05)$. Thus, $\mathrm{a}^{*}(0 \mathrm{~h}$ and $24 \mathrm{~h})$ and $\mathrm{b}^{*}(0 \mathrm{~h}$ and $24 \mathrm{~h})$ values in the longissimus dorsi muscle were significantly different among these three rabbit breeds $(p<0.05)$.

Least squares means for biceps femoris (Table 3) showed that that no significant differences existed for $\mathrm{L}^{*}{ }_{24 \mathrm{~h}}$ among the three rabbit breeds $(p>0.05)$. The $\mathrm{L}^{*}{ }_{0 \mathrm{~h}}, \mathrm{a}^{*}{ }_{0 \mathrm{~h}}$ and $\mathrm{a}^{*}{ }_{24 \mathrm{~h}}$ values were significantly higher in Tianfu Black rabbits than in Hyla and Champagne rabbits $(p<0.05)$. Tianfu Black rabbits had higher $\mathrm{b}^{*}{ }_{\mathrm{h}}$ values than Champagne rabbits $(p$ $<0.01)$, and $\mathrm{b}^{*}{ }_{0 \mathrm{~h}}$ values in Champagne rabbits were higher than in Hyla rabbits $(p<0.01)$.

Comparisons of meat color trait least squares means for longissimus dorsi muscle (Table 2) and biceps femoris muscle (Table 3) indicated that: 1) The value of $\mathrm{L}^{*}{ }_{24 \mathrm{~h}}$ in the three rabbit breeds was higher than that of $\mathrm{L}^{*}{ }_{\mathrm{h}}$ in both longissimus dorsi and biceps femoris muscles. However, the biceps femoris muscle had somewhat higher $\mathrm{L}^{*}{ }_{0 \mathrm{~h}}$ and $\mathrm{L}_{24 \mathrm{~h}}$ values than the longissimus dorsi muscle; 2) Values of $\mathrm{a}^{*}{ }_{0 \mathrm{~h}}$ and $\mathrm{a}^{*}{ }_{24 \mathrm{~h}}$ were larger in longissimus dorsi than in biceps femoris in the three rabbit breeds; and 3) Values of $b^{*}{ }_{24 h}$ were higher than those of $b^{*}{ }_{0 h}$ in the three rabbit breeds in the longissimus dorsi and biceps femoris muscles, and values of $\mathrm{b}_{0 \mathrm{~h}}{ }$ and $\mathrm{b}^{*}{ }_{24 \mathrm{~h}}$ were similar in both longissimus dorsi and biceps femoris muscles.

The meat color depends on the level of myoglobin, oxydo-reduction, the degree of oxidation of iron atoms, and on a possible denaturation of globin (Guidera et al., 1997; Monika et al., 2010; Newcom et al., 2004; Pla et al., 1996). Tianfu Black had the highest values for $\mathrm{a}^{*}{ }_{0 \mathrm{~h}}$ and $\mathrm{a}^{*}{ }_{24 \mathrm{~h}}$ indicating that meat from Tianfu Black rabbits had a darker red color than meat from the other two breeds. Higher $\mathrm{a}^{*}$ values in Tianfu Black were likely related to higher pigment content (Renerre, 1990). Champagne rabbits had the highest $\mathrm{b}^{*}{ }_{24 \mathrm{~h}}$ values in both longissimus dorsi and biceps femoris muscles. However, differences in $\mathrm{b}^{*}{ }_{24} \mathrm{~h}$ observed here among breeds were small, thus it is likely that consumers would be unable to distinguish differences in yellowness visually.

Pascual and Pla (2007) reported that selection for growth 
rate in rabbits would increase the oxidative metabolism route and change the meat color. However, Hernández et al. (2006) reported that selection for growth rate did not affect the main sensory characteristics of meat, such as tenderness, juiciness, and fibrousness, but it had a negative effect on aniseed odor, aniseed flavor, and liver flavor. Intense artificial selection for growth rate of meat-type birds has resulted in a higher incidence of abnormal conditions (e.g., PSE-like meat), however this has not been found in rabbit meat (Cavani et al., 2009). Several researchers reported that the pre-slaughter environment (e.g., housing temperature, rearing techniques, feeding regimens, transport conditions and time) influenced blood biochemical parameters and meat traits in rabbits (Combes et al., 2010; Corino et al., 2007; Sabuncuoglu et al., 2011), thus producers should offer rabbits suitable pre-slaughter environmental conditions to obtain high-quality meat.

Least squares means for longissimus dorsi (Table 2) indicated that Hyla rabbits had significantly higher IMF values than Champagne and Tianfu Black rabbits $(p<0.01)$, and that there were no significant differences between Champagne and Tianfu Black rabbits ( $p>0.05)$. Similarly, least squares means for biceps femoris (Table 3 ) showed that Hyla had a far higher IMF than the other two breeds $(p<0.01$; Table 3$)$. Thus, Hyla rabbits had substantially higher IMF values than other two breeds in both muscles. However, the biceps femoris IMF values were all larger than the corresponding longissimus dorsi IMF values for the three breeds. The IMF value here was far lower than the IMF value in lean meat (5.4 \pm 0.9$)$ found in hybrid rabbits produced by crossing two SIKA genotype lines in Slovenia (Polak et al., 2013). These authors reported that lean meat IMF content differed by genotype line, sex and age at slaughter and that IMF increased with age. Ouhayoun (1988) found differences in hind leg fat content among seven breeds of large, medium and small size rabbits slaughtered at 11 wk of age; large size breeds had lower fat content than small size breeds. Compared to pig meat, rabbit meat has a lower intramuscular fat and this intramuscular fat has a high percentage of unsaturated fatty acids and a low cholesterol level (Cavani and Petracci, 2008; Hernández et al., 2006). These characteristics give rabbit meat an advantage over pork when attracting consumers intent on buying healthy meat.

\section{Conclusions}

This study found differences in carcass and meat quality traits among three rabbit breeds. Tianfu Black rabbits had higher commercial carcass, head, skin, and thoracic viscera percentages than Hyla and Champagne rabbits. Tianfu Black had the lowest $\mathrm{pH}$ at $24 \mathrm{~h}$, the highest redness color values at 0 and $24 \mathrm{~h}$ post-mortem, and lower intramuscular fat percent than Hyla and Champagne. Conversely, Hyla rabbits had the highest $\mathrm{pH}$ values, lightness, and yellowness at $24 \mathrm{~h}$ as well as the highest intramuscular fat percentages. Based on results here, we recommend the Tianfu Black breed for commercial rabbit production.

\section{Acknowledgments}

This research was funded by the Tianfu Black rabbit breeding fund (Grant No. 2011NZ0099-4) in Sichuan province, the double-support projection of Sichuan Agricultural University, and the fund (Grant No. 12ZB095) for genetic polymorphism of MRFs in rabbit breeds in Sichuan province, China.

\section{References}

1. AOAC. (1980) Official Methods of Analysis. 13th ed. Association of Official Analytical Chemists, Washington, DC.

2. Blasco, A. and Ouhayoun, J. (1996) Harmonization of criteria and terminology in rabbit meat research. Revised proposal. World Rabbit Sci. 4, 93-98.

3. Blasco, A. and Piles, M. (1990) Muscular pH of the rabbit. Ann. Zootech. 39, 133-136.

4. Bolet, G., Brun, J. M., Lechevestrier, S., Lopez, M., and Boucher, S. (2004) Evaluation of the reproductive performance of eight rabbit breeds on experimental farms. Anim. Res. 53, 59-65.

5. Cavani, C. and Petracci, M., (2008) Qualità della carne di coniglio. In: I. Romboli, M. Marzoni Fecia di Cossato, A. Schiavone, L. Zaniboni, S. Cerolini (eds.) Avicoltura e Coniglicoltura. Point Veterinaire Italie, Milano, pp. 503-517.

6. Cavani, C., Petracci, M., Trocino, A., and Xiccato, G. (2009) Advances in research on poultry and rabbit meat quality. Ital. J. Anim. Sci. 8, 741-750.

7. Corino, C., Lo Fiego, D.P., Macchioni, P., Pastorelli, G., Di Giancamillo, A., Domeneghini, C., and Rossi, R. (2007) Influence of dietary conjugated linoleic acids and vitamin $\mathrm{E}$ on meat quality, and adipose tissue in rabbits. Meat Sci. 76, 19-28.

8. Combes, S., Postollec, G., Cauquil, L., and Gidenne, T. (2010) Influence of cage or pen housing on carcass traits and meat quality of rabbit. Anim. 4, 295-302.

9. Chiericato, G.M., Ravarotto, L., and Rizzi, C. (1994) Study of the metabolic profile of rabbits in relation to two different environmental temperatures. World Rabbit Sci. 2, 153-160.

10. D'Agata, M., Preziuso, G., Russo, C., Zotte, A.D., Mourvaki, E., and Paci, G. (2009) Effect of an outdoor rearing system on the welfare, growth performance, carcass and meat quality of a slow-growing rabbit population. Meat Sci. 83, 691-696. 
11. Dalle Zotte, A. (2002) Perception of rabbit meat quality and major factors influencing the rabbit carcass and meat quality. Livest. Prod. Sci. 75, 11-32.

12. Dalle Zotte, A. and Szendrõ, Z. (2011) The role of rabbit meat as functional food. Meat Sci. 88, 319-331.

13. FAOSTAT. (2010) http://faostat.fao.org/site/291/default.aspx.

14. Guidera, J., Kerry, J. P., Buckley, D. J., Lynch, P. B., and Morrissey, P. A. (1997) The effect of dietary vitamin E supplementation on the quality of fresh and frozen lamb meat. Meat Sci. 45, 33-43.

15. Hernández, P. and Gondret, F., (2006) Rabbit meat quality. In: L. Maertens, P. Coudert (eds.) Recent Advances in Rabbit Sciences. ILVO, Melle Belgium, pp. 269-290.

16. Mach, N., Bach, A., Velarde, A., and Devant, M. (2008) Association between animal, transportation, slaughterhouse practices, and meat $\mathrm{pH}$ in beef. Meat Sci. 78, 232-238.

17. Mazzone, G., Vignola, G., Giammarco M., Manetta, A. C., and Lambertini, L. (2010) Effects of loading methods on rabbit welfare and meat quality. Meat Sci. 85, 33-39.

18. Monika, P. S., L’ubica, C., Jozef, M., Andrea, L., Renáta, S., and Ján, R. (2010) Quality of Rabbit Meat and Phyto-Additives. Czech J. Food Sci. 28, 161-167.

19. Nath, D. R. and Rao, N. P. L. (1985) A comparison between domestic and wild rabbit as meat and fur producer. Indian $J$. Anim. Prod. Mgmt. 1, 136-140.

20. Newcom, D. W., Stadler, K. J., Baas, T. J., Goodwin, R. N., Parrish, F. C., and Wiegand, B. R. (2004) Breed differences and genetic parameters of myoglobin concentration in porcine longissimus muscle. J. Anim. Sci. 82, 2264-2268.

21. Niezwiadek, S., Kawinska, J., and Tuczynska, J. (1983) Production characteristics of rabbits of the White Termonde breed. Rocz. Nauk. Zoot. 10, 67-78.

22. NRC. (1977) Nutrient Requirement of Rabbits, Second revised edition. National Academy of Sciences. Washington, D.C.

23. Ortiz Hernández, J. A. and Rubio Lozano, M. S. (2001) Effect of breed and sex on rabbit carcass yield and meat quality. World Rabbit Sci. 9, 51-56.

24. Osman, A. M. A. (1991) Effect of reducing feeding time on the growth performance, carcass traits and meat quality of growing rabbits. Arch. Geflügelk. 55, 196-200.

25. Ouhayoun, J., and Delmas, D. (1988) Meat quality of rabbit. I. Differences between muscles in post mortem $\mathrm{pH}$. In: Proc. $4^{\text {th }}$ World Rabbit Congr., Budapest, Hungary, pp. 412-417.

26. Ouhayoun, J., Delmas, D., and Poujardieu, B. (1983) Variability in the myoglobine content of rabbit muscle. Relationships with energy metabolism. In: $2^{\text {nd }}$ International Colloquy "The rabbit as a model animal and breeding object", Rostock, Alle- magne, pp. 15-17.

27. Paci, G., Cecchi, F., Preziuso, G., Ciampolini, R., and D'Agata, M. (2012) Carcass traits and meat quality of two different rabbit genotypes. Ital. J. Anim. Sci. 11, 249-252.

28. Pascual, M. and Pla, M. (2007) Changes in carcass composition and meat quality when selecting rabbits for growth rate. Meat Sci. 77, 474-481.

29. Peiretti, P. G., Gai, F., Rotolo, L., Brugiapaglia, A., and Gasco, L. (2013) Effects of tomato pomace supplementation on carcass characteristics and meat quality of fattening rabbits. Meat Sci. 95, 345-351.

30. Pla, M., Hernández, P., and Blasco, A. (1996) Carcass composition and meat characteristics of two rabbit breeds of different degrees of maturity. Meat Sci. 44, 85-92.

31. Renerre, M. (1990) Review: factors involved in the diacoloration of beef meat. Int J. Food Sci. Tech. 25, 613-630.

32. Renou, J. P., Canioni, P., Valin, C., and Cozzone, P. J. (1986) Phosphorus-31 nuclear magnetic resonance study of post mortem catabolism and intracellular $\mathrm{pH}$ in intact excised rabbit muscle. Bioch. 68, 543-554.

33. Polak, T., Gašperlin, L., Rajar, A., and Žlender, B., Rotolo, L., Gai, F., Nicola, S., Zoccarato, I., Brugiapaglia, A., and Gasco, L. (2013) Dietary supplementation of oregano and sage dried leaves on performances and meat quality of rabbits. J. Integr. Agr. 12, 1937-1945.

34. Sabuncuoglu, N., Coban, O., Lacin, E., Ceylan, Z. G., Ozdemir, D., and Ozkan, A. (2011) Effect of pre-slaughter environment on some physiological parameters and meat quality in New Zealand rabbits (Oryctolagus cuniculus). Trop. Anim. Health Pro. 43, 515-519.

35. Terlouw, E. M. C. (2005) Stress reactions at slaughter and meat quality in pigs: Genetic background and prior experience. A brief review of recent findings. Livest. Prod. Sci. 94, 125-135.

36. Tùmová, E., Bízková, Z., Skøivanová, V., Chodová, D., Martinec, M., Van Laack, R. L., Liu, C. H., Smith, M. O., and Loveday, H. D. (2000) Characteristics of pale, soft, exudative broiler breast meat. Poultry Sci. 79, 1057-1061.

37. Vigneron, P., Bacou, F., and Ashmore, C. R. (1976) Distribution heterogeneite of muscles fiber types in the rabbit Longissimus muscle. J. Anim. Sci. 43, 985-988.

38. Watanabe, A., Daly, C. C., and Devine, C. E. (1996) The effects of the ultimate $\mathrm{pH}$ of meat on tenderness changes during ageing. Meat Sci. 42, 67-78.

39. Zeferino, C. P., Komiyama, C. M., Fernandes, S., Sartori, J. R., Teixeira, P. S. S., and Moura, A. S. A. M. T. (2013) Carcass and meat quality traits of rabbits under heat stress. Anim. 7, 518-523. 